cases with dangerous tendencies and direct mental impairment that compose the two great classes considered in this communication.

\section{MY EXPERIENCE WITH SOLANUM CAROLI- NENSE IN THE TREATMENT OF EPILEPSY.}

Tiead in the Section on Neurology and Medical Jurisprudence at the Forty-sixth Annual Meeting of the American Medical Association, at Baltimore, Md., May 7-10, 1895.

\section{BY C. F. BARBER, M.D.} BROOKLYN, N, Y.

In February 1893, my attention was called to the use of solanum carolinense in epilepsy; accordingly, I made an effort to learn something of its efficacy, also of its source before utilizing it in my practice.

I found solanum carolinense, or, as it is more commonly called, horse nettle, bull nettle or sand brier, was not official. It is not recognized by the $U$.S. Pharmacopoia, but a description, short, it is true, is found in the Dispensatory of 1894 . It is a native of Florida and Carolina but is found as far north as Connecticut; grows from one to two feet in height, branching, and is covered with shaggy hairs which are armed with stout, straight, yellowish prickles. The leaves have the same armor for defense as do the stem and branches. The berries which are the fruit of the shrub are utilized in preparing the pre. parations used in medicine, and when mature are of an orange yellow color. The shrule prefers a saudy soil for its growth and is most tenacious of life when once established.

Little has been written about the drug or its action, consequently there is little to review. Krauss isolated two active principles in 1894: solanin and solanidin. Only two preparations have thus far been used, the f. ext. and a 20 per cent. tincture.

The honor of placing this agent before the profession is due Dr. J. L. Napier of Blenheim, S. C. In 1889 his paper was read before the South Carolina Medical Society and after explaining the results of his observations among the negroes who use the berries in whisky, making a tincture, he concisely depicted its results in his hands, which, I may add, were exceedingly encouraging. Finding that the primary users of the berries were in the habit of administering them in cases of convulsions, the doctor secured some of the preparation used by the negroes and administered it to a case of epilepsy which had baffed the energies of all the medical men in the vicinity and obtained surprising results. One case after another, doing well under its employment, he gradually became a convert to it as a therapeutic remedy in epilepsy and allied disorders.

Dr. Geo. F. Foy, F.R.C.S., in Medical Press and Circular (Medical Age 1890, p. 18), refers to the results of Dr. Napier in a very complimentary manner and speaks as though he had much hopes from the drug.

In March, 1893, I obtained from Dr. A. G. Selman, of Indianapolis, a sample of the tincture. My wards at the Kings County Hospital having many epileptics among their occupants, I at once placed several upon the use of the remedy. At this time I subjected only those having the grand mal type of the disease to the use of the drug. From one to six convulsive seizures is the record of these patients for twentyfour hours.

As is the case in many instances where the drug is changed in the treatment of epilepsy, my immediate results were encouraging, for not a convulsion occurred for days. For several weeks the improvement continued, some of the patients brightening mentally. This latter condition may have been due simply to suspension of the bromid treatment. In a few instances, slight drowsiness, and in one case vertigo was complained of. These symptoms were quickly relieved by either lessening or suspending the quantity given.

The individual histories of this series of cases, I regret to acknowledge, have been lost or mislaid. I was not aware of this fact until after I had promised to prepare this paper at the solicitation of your worthy Secretary.

In two cases, one of epileptic insanity the other having mild epileptic seizures, I had the pleasure of noting marked improvement in each instance. The case of epileptic insanity had been under my care at times for six or seven years with little or no improvement. He had been subjected to all forms of treatment, but no favorable result, even for a short interval, was even noted until the drug in question was tried. The attacks occurred in this boy both at night and during the day, the periods of insanity lasting from a few hours to several days. While under the use of this drug, he brightened mentally and his convulsive seizures were reduced from three in twenty-four hours to two a week.

In a little girl who had mild epileptic seizures, two or three occurring each week, I had the satisfaction of knowing that her condition was so much improved that her parents considered her cured. I doubt this statement, but am willing to admit that the paroxysms were so mild in character that an untrained observer would consider them simply little nervous turns.

In no case, thus far, have I seen the seizure cease entirely, as has been the experience with some of my predecessors in the use of solanum. I have had no bad effects, save the slight dizziness spoken of and the drowsiness.

I must ask the pardon of this Section for presenting this incomplete report, but as I can add some more positive data I shall hope to be excused for placing the foregoing before this distinguished body.

My later investigations have been conducted with the fl. ext. of the drug obtained from Parke, Davis \& Co. The dose has ranged from half a drachm to half an ounce. The ages of the patients from 8 to 50 years, and the cases have comprised those suffering from epilepsy with idiocy, epilepsy with insanity, epilepsy with grand and petit mal and epilepsy from traumatism. The cases the results of trauma were of old standing and had been reported as cures, each having been operated upon. They had, however, from two convulsions in twenty-four hours to eight or ten in the same time.

In observing my last experimental cases, I have been greatly aided by the watchful care of Dr. F. Welker, who has carefully tabulated the results from day to day. Eight of the cases are attending the school for feeble-minded children which is an outgrowth of the idiot ward.

Of these, three are boys and five girls. The girls, who are in the habit of having epileptic attacks each day, did well for a period of three weeks, not a convulsion occurring. At the end of that time, however, I began to regret that I had ventured to test the usefulness of 
the drug, for at a most inopportune time they all had convulsions and from this relapsed into their former state, that is, the condition I found them in before beginning the use of solanum. Although the dose was pushed, no improvement was noted and the treatment was abandoned.

With the boys a different state of affairs prevailed. They had an outbreak a few days following the girls but milder. Another period of about a week's duration intervened, when they gradually relapsed into their epileptic state.

Among the epileptics who were subject of grand mal, I had about the same results as I had experienced with the male epileptic idiots, save that the period of improvement continued longer and the relapse was more gradual. Ten who were under the drug did not have a convulsion for twenty-nine days. Then a case which was in the habit of having from three to six seizures per week had a mild attack, not being obliged to lie down. This patient is mentally much brighter than he has been for some time and is now capable of doing light work about the ward, which is contrary to his condition in the past. He now has his epileptic attacks, but they are milder in form than previously. I will not take the time of this Section going into the histories of these cases, but briefly cite three or four cases as examples of my general results :

Michael D., age 19 years, has been a subject of epilepsy for a number of years (exact period unable to ascertain, patient being an idiot). Patient had one seizure per week for a long period before taking solanum carolinense. After placing the patient upon the use of the drug no improvement was noted.

Mary H., age 23 years, has been a subject of epilepsy since her menstruation first appeared, is mentally bright save a period of slight stupor after a convulsion. Before using the drug she averaged three convulsions per week. Under the use of solanum carlinense she had an equal number and they were more severe in character.

Henry K., age 35 years, has had epilepsy since 18 years of age. Attacks followed the kick of a horse. He will average one a day and very severe. Patient is violent at times. While under the use of the drug in question he had several a day and of great severity. These are examples of many cases of which I have histories, but illustrate results obtained in my hands by the use of solanum carolinense.

In the Medical News of recent date, Dr. E. D. Boudurant, of the Alabama Insane Asylum, has placed his experience before the profession and his results are no more flattering than mine. A few conclusions can be deduced from the work done with this drug:

1. That solanum carolinense is not a substitute for the treatment now generally accepted for epilepsy.

2. That it is a preferable substitute for the bromid treatment when compared with the biborate of soda.

3. That it unquestionably has an influence over the disease, although mild. It sufficiently controls the disease so as to warrant us in substituting it for a time to relieve our patients of the depression produced by the bromid treatment.

4. Its toxic effects are nil.

Dear Doctor :-Please direct the attention of your friends to our Journal. We will be pleased to send sample copies to any names you may suggest.

\section{THE SUPPIEMENTARY TREATMENT OF EPILEPSY.}

Read in the Section on Neurolology and Medicul Jurisprudence at the Forty-sixth Annual Meeting of the American Medical Association, at Baltimore, Md., May 7-10, 1895.

BY A. N. WILIJIAMSON, M.D. NEW LONION, CONN.

The brief paper to which I beg to call your attention for a few minutes is simply a plain commonsense talk on the treatment of epilepsy; my object being to point out how our ordinary methods of treatment may be supplemented and made more effective by closer attention to certain points too often considered of minor importance. I do not know that any one is able to tell us very much that is new in regard to the etiology or pathology of this disease, but we may hope to make some advance in the matter of treatment. I have lived with epileptics for the past fifteen years, have studied the disease in its various manifestations, and it is possible that what I have learned in regard to the minutiæ of treatment, the minor details which are beyond the reach of the general practitioner, may be of interest to you. I shall not speak of epilepsy due to organic disease, where the convulsion is a symptom merely, but to true epilepsy, where, so far as we know, the convulsion is the disease.

Now, we have the power through a certain remedy of controlling the manifestations of this disease to a certain extent, giving a patient certain relief for a month, three months, sometimes a year-when a relapse occurs. If the convulsions can be successfully warded off for so long a time, and the patient kept in apparent perfect health, are we not justified in the inference that, by proper treatment and care, that period of immunity may be prolonged, perhaps indefinitely? What causes the recurrence of the attacks after a year's immunity? Is it, or is it not a preventable cause? If we are using the bromids is it because, after a time, they cease to influence the system as they did at first? We do not think so. My experience leads me to the conclusion that the recurrence of the attack is due in most instances to preventable causes. There are three directions in which we can look for the causes of this recurrence:

1. To the constitution of the patient and his capacity for tolerating the requisite doses necessary to control the spasm.

2. To the condition of the digestive system.

3 . To the question of personal habits, exercise, occupation and personal discipline. As to medication, the bromids are, from their positive value, in such general use that, in considering remedies, it is hardly necessary to refer to any other agent. Yet, in spite of this absolute value and relative success, they are held in almost universal opprobrium by the laity everywhere.

People who write to me for advice nearly always ask the question: "Do you use the bromids?" to which an affirmative reply probably ends the correspondence. Is this opprobrium deserved, or can we trace the fault to other sources? The bromids exert a powerful effect upon the system and the physician can not do justice to the patient or to himself unless he watches the effect carefully from day to day graduating the dose to suit the varying conditions of the case. It is especially important in this disease and, in fact, in all diseases, to become early acquainted with the exact dose required in each individual case, 